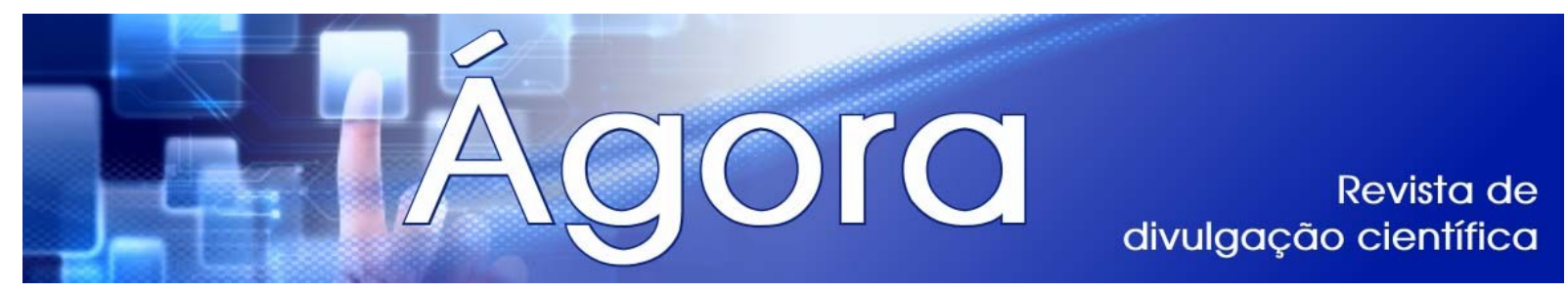

\title{
ANÁLISE DA RESPONSABILIDADE SOCIAL: EMPRESA DO RAMO FOSFOREIRO REFERENTE À QUALIDADE DE VIDA DOS TRABALHADORES
}

\author{
Franciele Wolinger Rocha ${ }^{1}$
} Simone Rocha ${ }^{2}$

\begin{abstract}
RESUMO: A qualidade de vida dos trabalhadores além de ser uma forma de agregar valor para a empresa é um dos princípios da responsabilidade social que será analisado na Empresa do Ramo Fosforeiro. Após promover atendimento médico na empresa observou a necessidade de orientação para os funcionários da qualidade de vida, que resulta para o trabalhador a melhora da qualidade de vida mental e física, e para a empresa a melhora no desempenho geral. Assim é necessário a analise quanto às condições de saúde, trabalho e bem estar social do empregado. $O$ recurso empregado na empresa União Fosforeira Ltda. foi o programa de qualidade de vida, que trabalha pontos para despertar a motivação e o comprometimento do colaborador com a organização. O que acaba integrando empregado e empresa, por que é um programa que a empresa oferece através da facilitação e orientação para atividades físicas, dietas saudáveis e avaliação física e médica para a saúde e bem estar do funcionário. A pesquisa caracteriza-se por um estudo descritivo com amostragem intencional de cinquenta colaboradores de diversos setores da empresa com análise estatística discutiva. Durante a pesquisa foi evidenciado que para um programa de qualidade de vida é necessário mais que o empenho da empresa, é imprescindível a sensibilização de todos, por que a importância dada para essa prática tem níveis diferentes, níveis esses relacionados à cultura das pessoas e a responsabilidade social. O que fica visível na apresentação dos resultados das análises dos dados decorrentes do programa da pesquisa.
\end{abstract}

Palavras-Chave: Qualidade de vida do trabalho. Responsabilidade Social. Motivação. Cultura.

ABSTRACT: The quality of workers' life, besides of being a way to add value to the company is one of the principles of social responsibility which will be discussed in the matchmaker's trade. After foster medical care in the company, it was observed the need for guidance in employees' quality of life, which results in mental and physical improvement for the worker and improvement in overall performances for the company. Therefore it is necessary to analyze the conditions of health, labor and welfare of the employee. The resource used in the company União Fosforeira Ltda. was the program quality of life, which works points to awaken the motivation and commitment of the employee with the organization. What ends up integrating

\footnotetext{
${ }^{1}$ Acadêmica do Curso de Administração da Universidade do Contestado (UnC). E-mail: franzinhaw86@yahoo.com.br

${ }^{2}$ Docente do Curso de Administração da Universidade do Contestado (UnC). E-mail: simonerocha253@hotmail.com
}

Ágora: R. Divulg. Cient., v. 18, n. 2, p. 64-90, dez. 2011 (ISSN 2237-9010) 
employee and company, because it is a program that the company offers through the facilitation and guidance for physical activity, healthy diets and physical and medical evaluation of the employee's health. The research is characterized by a descriptive study with purposive sampling from fifty employees from various sectors of company with statistical analysis. During the research it was shown that for a program of quality of life, it takes more than the company's commitment, it is essential to raise awareness of all, because the importance given to this practice has different levels, levels related to the culture of the people and social responsibility. What is visible in the presentation of the data's analysis' results, resulting from the research program.

Key-Words: Quality of work's life. Social Responsibility. Motivation. Culture.

\section{INTRODUÇÃO}

A União Fosforeira LTDA. iniciou suas atividades em 2001, da união das empresas Indústrias de Fósforos Catarinense e Industrias de Fósforos Latorre, ambas do ramo fosforeiro. Produz fósforos das marcas QUELUZ, GUARANI. ARGOS, TROPICAL E VITÓRIA, os fósforos são vendidos em todos os estados brasileiros. E as principais matérias primas utilizadas são madeira, clorato de potássio, parafina, cola e papelão. A empresa possui aproximadamente 500 colaboradores, e está situada a Rod. BR 470, Km 248, Distrito Industrial, Curitibanos, Santa Catarina (UNIÃO FOSFOREIRA, 2011).

O perfil dos colaboradores era de baixa escolaridade, baixo poder aquisitivo, moradia precária, pouca cultura, mas assim como a empresa esta mudando sua visão os funcionários também estão buscando voltar para a escola, hoje temos um índice de $37,9 \%$ de pessoas com ensino médio completo. Nos últimos anos muitos adquiriram bens como casa e carro, e se mostram mais interessados com a saúde e cultura. Quando pedimos sugestões as respostas foram pedidos de academia ou ginástica aeróbica na empresa, dicas de melhor alimentação, bibliotecas e treinamentos diversos.

Com base nesses dados foi realizada a pesquisa e desenvolvido o programa de qualidade de vida para análise das relações da Responsabilidade Social da empresa, pertinente a saúde, trabalho e bem estar social. O objetivo também foi de análise das ações desenvolvidas pela empresa em relação ao trabalhador e as melhorias resultantes, além de utilizar os dados obtidos do estudo para melhor integração de empregado e empregador. 


\section{RESPONSABILIDADE SOCIAL E CIDADANIA}

O movimento em torno da responsabilidade social no Brasil iniciou na década de 1980, impulsionado por uma sequência de eventos sociais, a ênfase nas questões sociais e ambientais mudou o comportamento do cidadão brasileiro. Expandindo os movimentos sociais, partidos políticos, organizações ambientais e associações de defesa dos direitos do consumidor, das mulheres e das crianças. Desde 2001 é realizado anualmente no Brasil, o Fórum Social Mundial, esses acontecimentos provocaram uma série de mudanças no mundo empresarial, várias entidades empresariais foram criadas para lidar com temas sociais, direitos humanos e sustentabilidade ambiental, incentivando o desenvolvimento comunitário e social e difundindo a responsabilidade corporativa (MELO NETO; FROES, 2001).

O estado é o primeiro setor, o mercado o segundo setor, e o terceiro setor são os movimentos sociais diversos e ONGs (Organizações Não Governamentais), que assumiram o papel de fiscal da sociedade cobrando do governo ações que o mesmo deixa de executar. A Responsabilidade Social vai além do universo de sócios e acionistas, muitas atividades acabam contribuindo com a comunidade local, para o meio ambiente e para muitos outros aspectos da sociedade.

O assunto Responsabilidade Social muitas vezes é confundido com ação social ou filantropia, que são ações que causam impacto temporário, como dar um prato de comida, a primeira é mais ampla e abrangente, como educação e treinamentos. Preconiza que quem recebe seus benefícios esta em desenvolvimento e evoluindo e as prioridades são intrínsecas, primeiramente os funcionários e na sequência os fornecedores e clientes, e a comunidade.

A responsabilidade social deve ser interpretada como um conjunto de princípios que direciona ações e relações da empresa com funcionários, fornecedores, consumidores e comunidade e assim contribuiu para o desenvolvimento social. É o comprometimento permanente dos empresários de adotar um comportamento ético e contribuir para o desenvolvimento econômico, melhorando a qualidade de vida de seus empregados e de suas famílias, da comunidade local e da sociedade geral. 
A responsabilidade social faz parte de um conceito mais amplo, o Desenvolvimento Sustentável, e dentro das suas dimensões a responsabilidade social é a mais complexa, porque compreendem os direitos humanos, dos empregados, dos consumidores, envolvimento comunitário, relação com fornecedores, monitoramento e a avaliação de desempenho e os direitos dos grupos de interesse. De acordo com Melo Neto e Froes, (2001, p. 79)

O objetivo é assegurar o desempenho ético correto e o desempenho ambiental adequado da empresa, melhorar a qualidade de vida de seus funcionários e dependentes, usar o poder e a relação da empresa com seus fornecedores e concorrentes para mobilizá-los a ser socialmente responsáveis (por exemplo, não comprar de nenhum fornecedor que usa trabalho infantil), implementar normas de respeito ao consumidor e mobilizálo para atos de solidariedade, utilizar todos os espaços de comunicação para transmitir valores e informações de interesse da comunidade, etc.

Atualmente o número de pessoas escolarizadas, o limite dos recursos naturais, o grande acesso a informações, não são fatores conjunturais ou passageiros, são características fundamentais da nossa sociedade e do nosso tempo que exige uma adaptação do mundo dos negócios e de todos nós. A responsabilidade social empresarial passa a ser considerada com relação às tomadas de decisões, nas soluções de problemas, e nas explorações de novas oportunidades, identificada como tema permanente.

Analisando o fator competitividade numa linha do tempo, temos como $1^{\circ}$ identificador de competitividade 0 preço de seus produtos, $2^{\circ}$ a qualidade, mas focada nos produtos e serviços, e hoje as empresas devem investir no permanente aperfeiçoamento de suas relações como todos os públicos dos quais dependem e com os quais se relacionam: clientes, fornecedores, empregados, parceiros, colaboradores, comunidade e o governo. Entende-se que

\footnotetext{
Para o empresário, a responsabilidade social da empresa está associada ao seu desempenho e ao consumo de recursos que pertencem à sociedade. $\mathrm{O}$ desempenho da empresa depende da utilização dos recursos naturais, renovações ou não, que não pertencem à empresa, mas à sociedade. Ao deles usufruir em beneficio próprio, a empresa contrai uma dívida social para com a sociedade, ou, como afirma o empresário, para com a humanidade (MELO NETO; FROES, 2001, p. 83, grifo do autor).
}

O negócio baseado em princípios socialmente responsáveis além de cumprir as suas obrigações legais, tem suas relações éticas e transparentes, quem aposta 
em responsabilidade e diálogo vem conquistando mais clientes e o respeito da sociedade.

O movimento da responsabilidade social decorre de três fatores que marcaram a época atual:

-A revolução tecnológica (satélites, telecomunicações), que eliminou distâncias e multiplicou a troca de informações via televisão, jornais, rádio, telefone e internet;

-A revolução educacional, que é consequência do número cada vez maior de pessoas que e frequentam escolas e querem mais informações;

-A revolução cívica, que é representada por milhões de pessoas organizadas de todo o mundo reunidas em associações e organizações não governamentais (ONGs) defendendo seus direitos e seus interesses, como a promoção social e a proteção ambiental.

\section{CERTIFICAÇÃO DA RESPONSABILIDADE SOCIAL}

Para implantar a responsabilidade social dentro da empresa buscando certificações, pode se usar a NBR 16000 ou a SA 8000. A diferença entre elas é que a SA 8000 é uma certificação de caráter multinacional lançada em 1997 pela SAI (Social Accountability International) com conceitos muito fortes de proteção à criança, ao trabalhador em regime semiescravo, à saúde, segurança e discriminação. A NBR 16000 é uma norma da ABNT (Associação Brasileira de Normas Técnicas) lançada em 2004 que, além de conter esses critérios, é mais sistêmica e bem planejada, que se preocupa mais com que a empresa crie um sistema de gestão de responsabilidade social eficaz. Com a finalidade de se criar uma norma com referência mundial como NBR 16000, em breve será lançada a ISO 26000, que abrangerá o conceito das normas SA e NBR de forma aprimorada (CHELEGON, 2008).

O objetivo de certificação é atestar a responsabilidade social da empresa, comprovar o exercício da sua responsabilidade social interna e externa, avaliar sua condição de empresa-cidadã e demonstrar que seus produtos são socialmente corretos. 
O processo de certificação social avalia o processo produtivo, as relações com a comunidade e as relações com os empregados e seus dependentes. Quando avaliam o processo produtivo é verificado se a empresa viola os direitos humanos ou se desrespeita os direitos do trabalho. Também avalia aos fornecedores que integram a cadeia produtiva, verificando a não ocorrência de quaisquer tipos de violações e desrespeito às legislações vigentes, o resultado é o produto socialmente correto.

Nas relações com a comunidade a avaliação concentra-se em aspectos como a natureza das ações sociais desenvolvidas pela empresa, ações de voluntariado, de doação, de apoio e projetos sociais próprios. Outros aspectos são os tipos de problemas sociais que constituem o alvo das ações sociais, os beneficiários (comunidade no geral), número e características de parceiros envolvidos, foco e escopo dessas ações.

E nos aspectos das relações com os empregados e seus dependentes, a avaliação focaliza o gerenciamento dos benefícios e sua extensão para os dependentes dos empregados, a gestão do clima organizacional (motivação, participação, compromisso) e da qualidade de vida no trabalho (relações interpessoais, atividades culturais, esportivas, sociais, assistência médica, etc), além de programas de desenvolvimento do colaborador.

\section{EMPRESA CIDADÃ}

O conceito de empresa-cidadã surgiu decorrente do movimento da consciência social, que tem como objetivo formar uma nova imagem empresarial para empresas que se convertem em tradicionais investidoras em projetos sociais. É notório que

\footnotetext{
Uma empresa-cidadã tem no seu compromisso com a promoção da cidadania e o desenvolvimento da comunidade os seus diferencias competitivos. Busca desta forma, diferenciar-se dos seus concorrentes assumindo uma nova postura empresarial - uma empresa que investe recursos financeiros, tecnológicos e de mão-de-obra em projetos comunitários de interesse público (MELO NETO; FROES, 2001, p. 100).
}

A cidadania empresarial corresponde ao exercício pleno de responsabilidade social pela empresa. Esta se torna cidadã quando contribuiu para o desenvolvimento 
da sociedade através de ações sociais suprindo as principais carências em ternos de serviços e infraestrutura de caráter social.

\section{QUALIDADE DE VIDA NO TRABALHO}

As empresas que agem com responsabilidade social devem estar preocupadas com a qualidade de vida dos trabalhadores assim como devem implementar ações para contribuir com a qualidade de vida. Dando condições plenas para realização pessoal e profissional. Com a necessidade de ganhar destaque no mercado as empresas, passaram a buscar a qualidade total que vem acompanhada pela qualidade de vida no trabalho e o foco esta no potencial humano.

A construção da qualidade de vida no trabalho ocorre com a implantação de melhorias e inovações gerenciais e tecnológicas no ambiente de trabalho. A empresa e empregado passam a ser vistos como um todo, o que é conhecido como enfoque biopsicossocial, que é o fator diferencial para campanhas, criação de serviços e implantação de projetos para manter e desenvolver as pessoas da organização.

A adoção de programas de QVT proporciona maior resistência ao estresse, estabilidade emocional, motivação, eficiência no trabalho, melhor autoimagem e melhor relacionamento. Assim beneficiariam a empresa com uma força de trabalho mais saudável, produtiva, melhor imagem e melhor ambiente de trabalho, em contrapartida menor absenteísmo, rotatividade, número de acidentes, menor custo de saúde assistencial.

De acordo com De Masi (2000, p. 330): "O novo desafio que marcará o século XXI é como inventar e difundir uma nova organização, capaz de elevar qualidade de vida e do trabalho, fazendo alavanca sobre a força silenciosa do desejo de felicidade".

Passamos a maior parte das nossas vidas dentro das organizações que trabalhamos, não seria mais que natural que passássemos nossas horas de trabalho com qualidade de vida, satisfação e alegria. Conforme Dolan (2006, p. 30)

Os resultados e a eficiência da empresa são normalmente avaliados em termos de lucro econômico, posição no mercado, qualidade dos produtos ou serviços, e possibilidades de competitividade no médio e longo prazo. $\mathrm{O}$ bem-estar e as doenças do individuo, em geral, não são considerados 
resultados da empresa, nem mesmo parcialmente. Numa situação em que a vantagem primordial perante a concorrência provenha da qualidade dos recursos humanos disponíveis, oferecer qualidade de vida ao trabalho é um modo de garantir mais comprometimento dos empregados com a missão e com os objetivos da empresa.

A qualidade de vida tem três dimensões relativa a saúde, a dimensão física que é a percepção do estado físico de saúde, é a ausência de enfermidades, ser saudável. A dimensão psicológica que é a percepção dos estados cognitivos e afetivos, como medo, ansiedade, falta de comunicação. Falta de autoestima e incerteza em relação ao futuro. Faz parte também crenças pessoais, espirituais e religiosas, o que inclui o significado de vida e disposições relativas ao sofrimento. E a terceira dimensão, a social que é a percepção das relações interpessoais, e de papéis sociais como apoio social e familiar e a permanência no emprego.

Deve existir nas organizações o verdadeiro bem-estar físico, moral e social no local de trabalho, e isso não é justificado somente pela ausência de trabalho ou doenças. O objetivo é evitar riscos sociais, como estresse, assédio, depressão, ansiedade e os riscos associados à dependência de álcool, drogas e outras substâncias químicas.

Para implementar uma metodologia de qualidade de vida na empresa, precisa primeiro identificar os fatores de riscos, fazer o diagnóstico, através de avaliações, exames, observação direta, entrevista particular com os colaboradores. Analisar os dados obtidos com essas ações, assim identificar se há casos especiais para tratamento individual, identificar pontos fracos dos grupos por cargo. Depois de analisados os resultados, deve-se estudar e definir metodologias mais apropriadas para minimizar os fatores de risco, e passamos para o estágio da intervenção que são implantadas todas as providências definidas nos planos para controlar os fatores de risco.

Para medir e quantificar os riscos psicossociais sua incidência ou ausência, definindo as probabilidades do fator de risco e a eficácia do programa utilizou a avaliação dos resultados. E para finalizar temos o acompanhamento e controle que se divide em dois segmentos: o primeiro consiste em controles periódicos que definam a predominância ou a redução do fator de risco, e o segundo é avaliado no final do programa avaliando se foram cumpridos os objetivos por meio das medidas de controle. 


\section{ESTRESSE OCUPACIONAL}

O estresse ocupacional é a resposta do organismo ao extremo e contínuo esforço físico, atividades repetitivas, pressão por metas e resultados, muita exigência e poucos recursos no ambiente de trabalho. $O$ trabalhador não sente mais prazer na realização de tarefas o que resulta em modificação de comportamento, apresentando dificuldades como ter um sono de qualidade ou de relacionamento, dores de cabeça ou problemas gastrointestinais. Isto acontece por que em estado de estresse o organismo permanece em atividade, reduzindo a capacidade de reação e defesa, ocasionando esgotamento físico e psicológico.

A relação entre o estresse emocional e as doenças humanas está vinculada ao sistema imunológico, que quando sofre "abusos", no caso do estresse crônico, há resultados suficientes de pesquisas para indicar que sua função decai, e assim aumenta a suscetibilidade de doenças infecciosas, câncer e doenças autoimunes.

O comum na nossa linguagem cotidiana é a administração do tempo, saber conduzir essa habilidade no trabalho não significa trabalhar mais, mas sim trabalhar melhor, e o estresse pode ser um aspecto nocivo a essa administração de tempo, há contribuintes internos, as nossas atitudes e os contribuintes externos que são padrões de comportamento, atitudes de outras pessoas.

As técnicas de relaxamento estão sendo muito eficazes no tratamento de muitos problemas relativos à tensão, como hipertensão, dores de cabeça provocadas pela tensão, asma brônquica e tensão em geral. A ioga é uma técnica de relaxamento que equilibra os sistemas do corpo: o sistema nervoso central, o sistema endócrino e o sistema digestivo. Ao desacelerar as atividades mentais e alongar suavemente o corpo, e massagear os órgãos internos a ioga nos proporciona uma sensação relaxante, e nos faz esquecer ou desviar atenção temporariamente de afazeres ou preocupações relacionados ao estresse.

Maneiras para reduzir o estresse ocupacional:

\section{Prevenção primária}

- Ergonomia;

- Definição de funções e desenho do ambiente;

- Sintonia fina da organização e da gestão; 


\section{Prevenção secundária}

- Educar e instruir os colaboradores;

\section{Prevenção terciária}

-Elaborar sistemas de gestão mais sensíveis, com a maior capacidade de reação e melhora dos serviços de atendimento à saúde ocupacional (ORGANIZAÇÃO MUNDIAL DA SAÚDE, 2004 apud. DOLAN, 2006, p.204).

\section{METODOLOGIA}

Para desenvolver essa pesquisa foi utilizado além do material teórico ao qual nos proporcionou a base para o desenvolvimento da mesma, um questionário que foi aplicado com os funcionários, além da solicitação e indicação de um nome para fazer parte do comitê do Programa da Qualidade de Vida no Trabalho. A partir de dados coletados foi analisado o material em dois aspectos: empregado e empregador.

Foi solicitada também para os funcionários envolvidos no programa Qualidade de Vida no Trabalho, uma relação atualizada de exames médicos. Após os resultados foi feita a avaliação física para assim ter um diagnóstico com base no questionário, exames de saúde e físico dos colaboradores. Foi realizada uma reunião com todos os envolvidos no projeto para sugestões e críticas nas condições sociais atuais da empresa e para os critérios do programa Qualidade de vida no trabalho. Posteriormente foi deixada nos setores da produção uma urna para que os funcionários deixassem suas dúvidas e sugestões de melhorias.

Os colaboradores foram escolhidos aleatoriamente e analisados pela avaliação médica e pelo o histórico funcional dos últimos seis meses, priorizando os que apresentarem necessidade de melhora de hábitos de vida, tendo os mesmos a opção de aceitar ou não participar. A princípio o programa atendeu uma amostra de 50 pessoas dos setores: RH, Serra, Tornos de laminação, Caixa e gaveta, Contínuas, Depósito e Manutenção.

Ocorreram ainda, encontros com o comitê do Programa Qualidade de Vida no Trabalho, para desenvolver o plano de ação para criação de informativos com dicas, e informações sobre saúde, alimentação, exercícios físicos e atividades sociais. Sendo assim, foi realizada uma avaliação do programa qualidade de vida no 
trabalho através de uma pesquisa de satisfação com os participantes do programa, e apresentação para o comitê dos resultados obtidos no exercício do programa. Havendo eficácia o programa será implantando em toda a organização e disponibilizado para todos os interessados.

\section{APRESENTAÇÃO E ANÁLISE DOS DADOS}

Durante o programa foi realizado um questionário com perguntas para mensurar o envolvimento dos participantes e observar estatisticamente a relação com tempo de empresa, idade, sexo e interesse pelas ações que o programa ofereceu.

Gráfico $1-$ Sexo

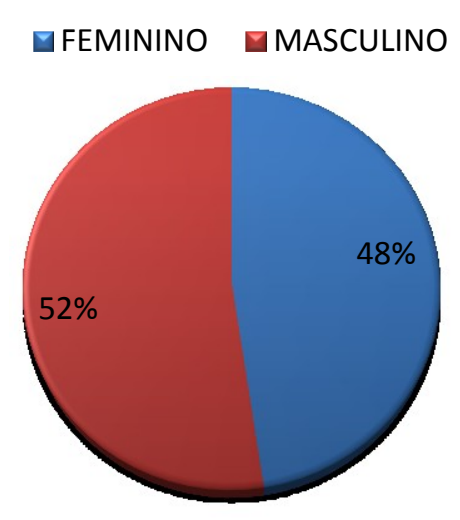

Fonte: Dados da pesquisa (2012)

$\mathrm{Na}$ amostra de 50 pessoas para participar do programa assim como para responder os questionários, o número de mulheres e homens foi semelhante, o número total de funcionários é praticamente metade homens e metade mulheres. Apesar de ambos terem diferentes visões, o interesse por um programa de qualidade de vida foi geral dos dois sexos, com $52 \%$ dos participantes homens e $48 \%$ mulheres. 
Gráfico 2 - Faixa Etária

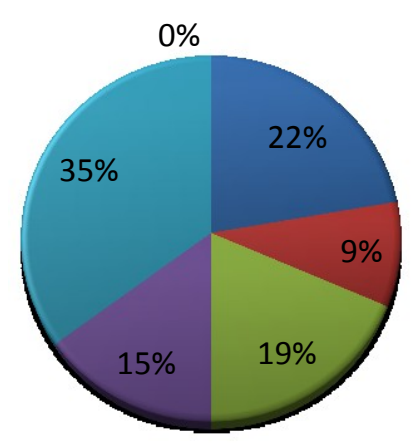

$\square 18$ À 25 ANOS

Q26 À 30 ANOS

$\square 31$ À 40 ANOS

$\square 41$ À 50 ANOS

$\square 51$ À 64 ANOS

$\square$ MAIS DE 65 ANOS

Fonte: Dados da Pesquisa (2012)

A faixa etária dos funcionários varia de 18 anos até 60 anos, há pessoas que trabalharam a vida toda na empresa assim como tem pessoas que estão tendo a primeira oportunidade de emprego. Não existe distinção para contratação por conta de idade, é necessário pessoas de todas as idades pela complexidade e diferenças das funções. O número de funcionários com mais de 51 anos foi predominante no programa.

Gráfico 3 - Escolaridade
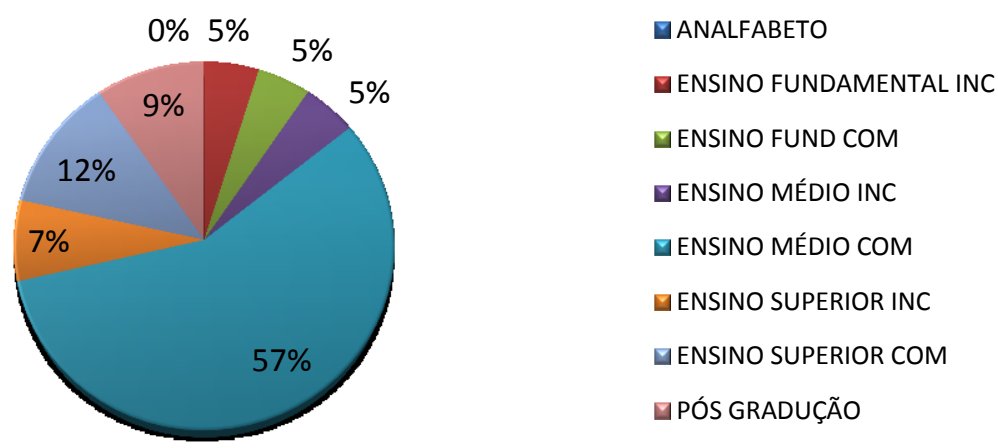

Fonte: Dados da Pesquisa (2012)

Devido a uma parceria da empresa com o SESI, muitos trabalhadores tiveram o privilégio de voltar a estudar, muitos fizeram o ensino fundamental e médio pela empresa. As aulas aconteciam na empresa mesmo e os funcionários tinham transporte e lanche gratuito. Depois das primeiras turmas formadas foi ficando cada vez mais escasso o número de alunos e acabaram as turmas, pois era necessário ter um determinado número de pessoa para poder continuar. Mas temos um número 
significativo de pessoas que tem grau de escolaridade ensino médio completo, que representa $57 \%$ dos funcionários que participaram do programa.

Mas ainda temos na empresa um pequeno número de analfabetos que não participaram da pesquisa. E outras pessoas que estão cursando graduação ou que já tem estudos acima disso são representadas pelos trabalhadores do setor administrativo, SESMT e depósito.

Gráfico 4 - Setor

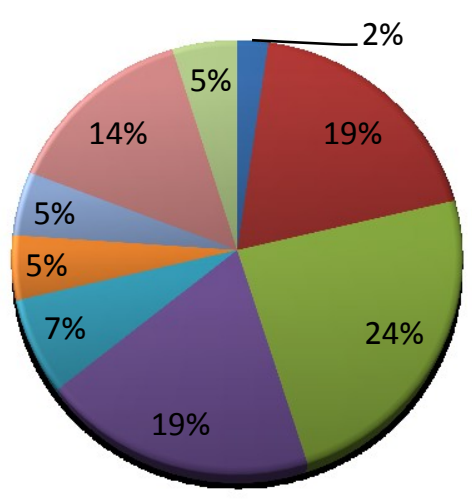

IALMOXARIFADO

aADMINISTRATIVO

$\square$ CONTÍNUAS

GAIXA E GAVETA

$\square$ GERAL

$\square$ QUÍMICA

$\square$ OFICINA

Fonte: Dados da pesquisa (2012)

O questionário foi aplicado em representantes de todos os setores, para ter envolvimento de todas as pessoas. $\mathrm{E}$ consequentemente setores com maior número de funcionários tiveram mais participantes, e em setores com maior disponibilidade e interesse das pessoas, como o administrativo, todos os integrantes participaram (19\%). O interesse implica da questão cultural e até mesmo do conhecimento da importância de uma alimentação saudável, da pratica de um exercício físico e de praticar outras atividades que fazem bem pra mente e para o corpo.

Gráfico 5 - Tempo de trabalho na empresa

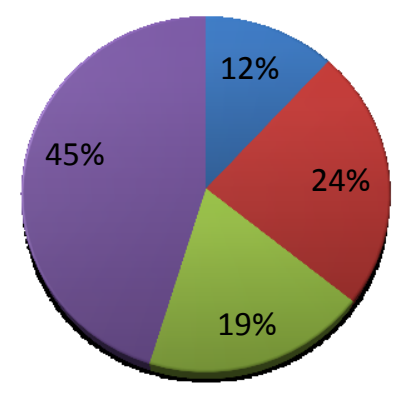

$\square$ ATÉ 1 ANO

Q 2 A 5 ANOS

$\square 5$ A 9 ANOS

$\square 10$ ANOS

Fonte: Dados da pesquisa (2012)

Ágora: R. Divulg. Cient., v. 18, n. 2, p. 64-90, dez. 2011 (ISSN 2237-9010) 
Apesar da rotatividade justificada pelo salário, horário de trabalho, novas empresas que entraram no mercado da região, e mais uma vez menciona-se a cultura, ainda tem um número significativo de funcionários que trabalham na empresa há vários anos $(45 \%)$. A rotatividade maior acontece no tempo de trabalho de um ano, e geralmente com pessoas nos dois primeiros grupos de idade.

Gráfico 6 - Participação em cursos de aperfeiçoamento profissional

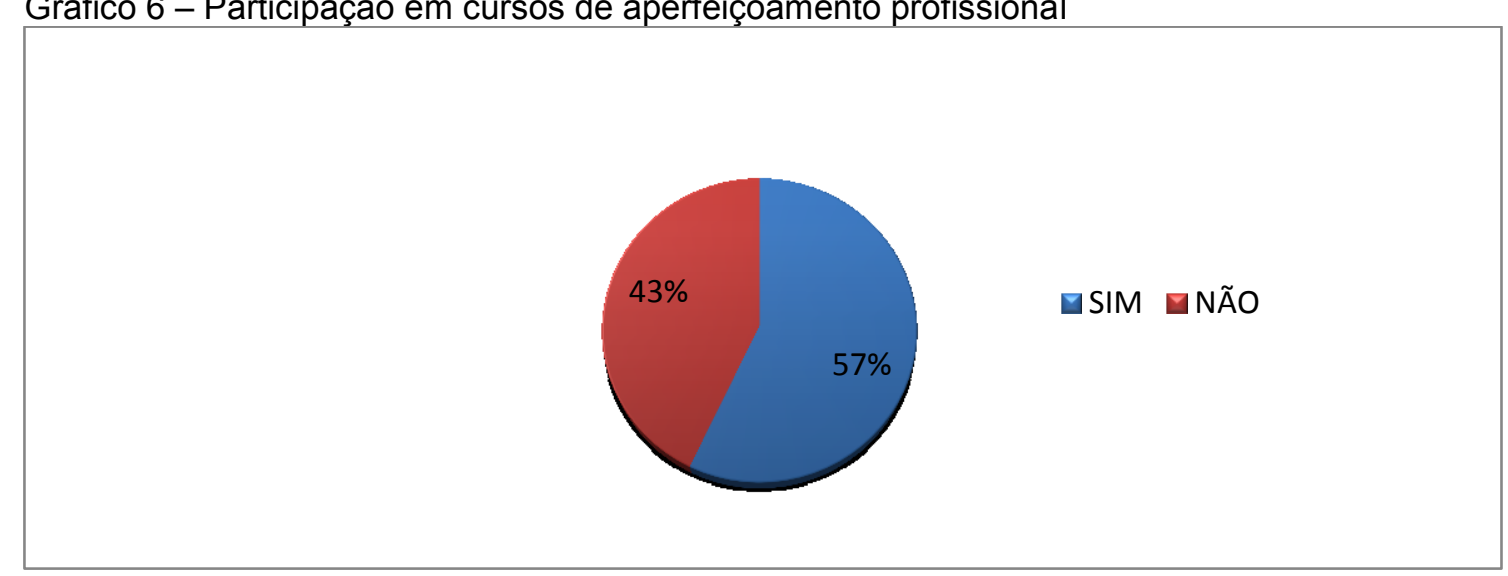

Fonte: Dados da pesquisa (2012)

A empresa oferece durante 0 ano vários cursos de aperfeiçoamento profissional, treinamentos específicos e conforme o andamento das atividades treinamentos variados. Nesse ano de 2012 os treinamentos de integração e da qualidade foram prioridade, assim hoje $100 \%$ dos funcionários novos passaram pela a integração e $100 \%$ no geral dos funcionários foram capacitados pelo treinamento da qualidade.

O treinamento de integração acontece um dia antes do início das atividades de empresa, onde são passadas informações da política da empresa, dos benefícios oferecidos, regras de segurança e informações necessárias na integração do funcionário. E o treinamento da qualidade explica a política da qualidade, a importância da função de cada pessoa para a qualidade do processo e do produto, e é realizada a visita pela fábrica para conhecimento de todo o processo. Assim como também tem treinamentos específicos da função, treinamentos para os líderes e para o administrativo. 
Gráfico 7 - Participa das atividades físicas realizadas na empresa

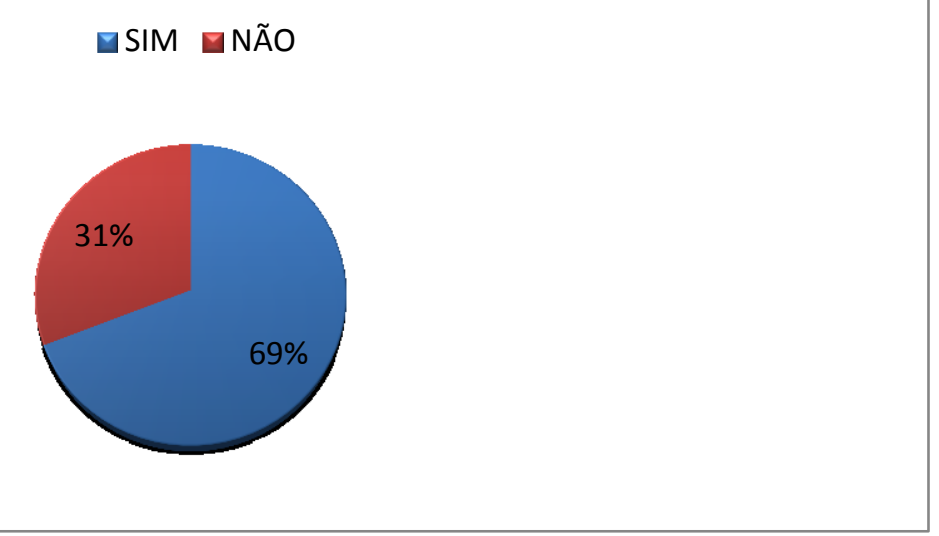

Fonte: Dados da pesquisa (2012)

$\mathrm{Na}$ empresa são realizadas atividades físicas duas vezes por semana, divididos por setor, essa atividade é a ginástica laboral, que traz benefícios fisiológicos, psicológicos e sociais, porque além de ser uma forma de alongamento é também um momento de descontração, de relaxamento, e quando a pessoa volta para seu trabalho pode se concentrar melhor na função. É disponibilizada a academia para quem faz parte do programa de qualidade de vida. Dos participantes do programa $69 \%$ praticam as atividades físicas realizadas na empresa, a ginástica laboral.

Gráfico 8 - Realiza atividades físicas fora da empresa

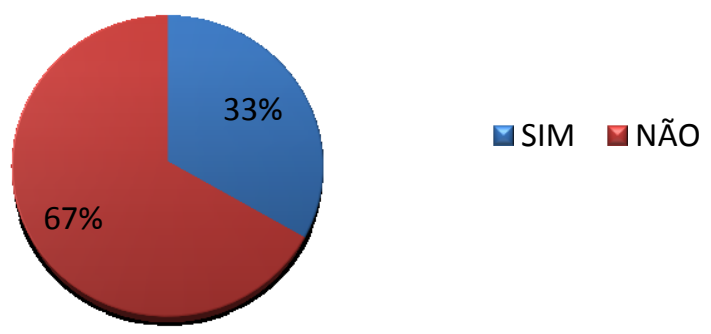

Fonte: Dados da pesquisa (2012)

Qualquer atividade física é válida, seja caminhada, futebol, academia, vôlei, exercícios físicos trazem inúmeros benefícios para o organismo, e depois que se adquire o hábito de praticar fica mais fácil. Das pessoas que fazem parte do programa $67 \%$ procuram realizar mais atividades fora da empresa.

Benefícios dos Exercícios Físicos:

Ágora: R. Divulg. Cient., v. 18, n. 2, p. 64-90, dez. 2011 (ISSN 2237-9010) 
-Queima de calorias e perda de peso;

-Manutenção da tonificação dos músculos;

-Melhoria na circulação;

-Melhoria nas funções cardíacas e pulmonares;

-Aumento do autocontrole;

-Redução do estresse;

-Aumento da habilidade de concentração;

-Melhoria na aparência;

-Redução da depressão;

-Melhoria na qualidade do sono;

-Prevenção de pressão sanguínea, colesterol alto e diabetes;

-Nas crianças, pode ajudar no desenvolvimento das habilidades psicomotoras (BELEZA E SAÚDE; 2012).

Gráfico 9 - Sofreu algum acidente de trabalho no ano que passou

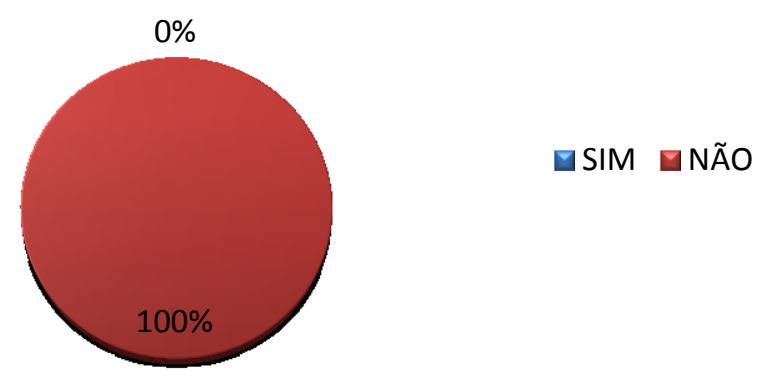

Fonte: Dados da pesquisa (2012)

Dentre as várias causas de acidente de trabalho podemos citar a falta de atenção do funcionário, falta de segurança e falta de orientação. E muitas vezes o estresse ocupacional que acaba causando essa distração, em muitos casos a pessoa vem trabalhar esgotada, não dorme direito, e quando insatisfeitos com algo parece que nada mais que realiza da certo, e isso pode refletir no trabalho, na vida pessoal e na vida social.

Nessa pesquisa trabalhamos com amostra, por isso não apresentou nenhum acidente, mas nos últimos anos os acidentes estão cada vez menores, pela questão 
de orientação com treinamentos e troca de função do funcionário quando necessário.

Gráfico 10 - Afastamentos por motivo de doença

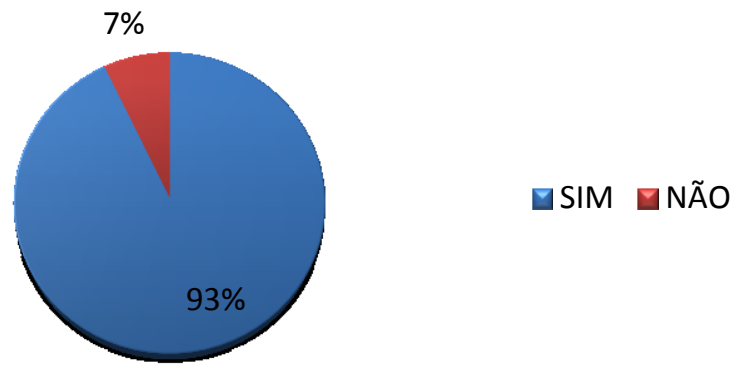

Fonte: Dados da pesquisa (2012)

Os afastamentos são tanto por problemas ligados a função que exercem como doenças hereditárias ou não ligadas ao trabalho. Com base nisso esta sendo realizado o programa de qualidade de vida, por que muitos problemas podem diminuir com atividades físicas, alimentação saudável e um acompanhamento médico. A melhora da qualidade de vida dos trabalhadores contribui para melhoria continua da empresa, que é um objetivo tão almejado pelas organizações hoje, refletindo na produtividade, rotatividade, absenteísmo, e afastamento por motivo de doença. O que fica evidente com o significativo $93 \%$ que nunca se afastarão por motivos de doença.

Gráfico 11 - Participação de atividades culturais promovidas pela empresa

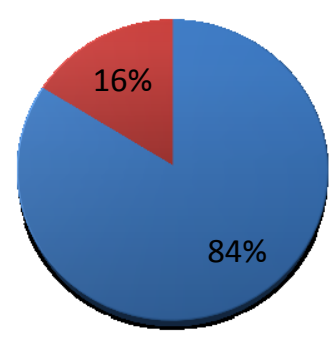

Fonte: Dados da pesquisa (2012) 
Quando a empresa promove alguma atividade cultural, no geral o número de colaboradores participantes é grande, pela amostra $84 \%$ das pessoas participam. Anualmente a empresa disponibiliza aos homens campeonato de futebol, durante todo ano são realizadas palestras de diferentes temas, e também são distribuídos folders com informações relativos à saúde, beleza, alimentação. Mensalmente são atualizados informativos nos murais sempre com diferentes informações do interesse dos trabalhadores. A intenção para o próximo ano é de adotar a biblioteca circulante, para os funcionários que tem o hábito e gosto por leitura poderem trocar livros.

Gráfico 12 - Fatores de motivação

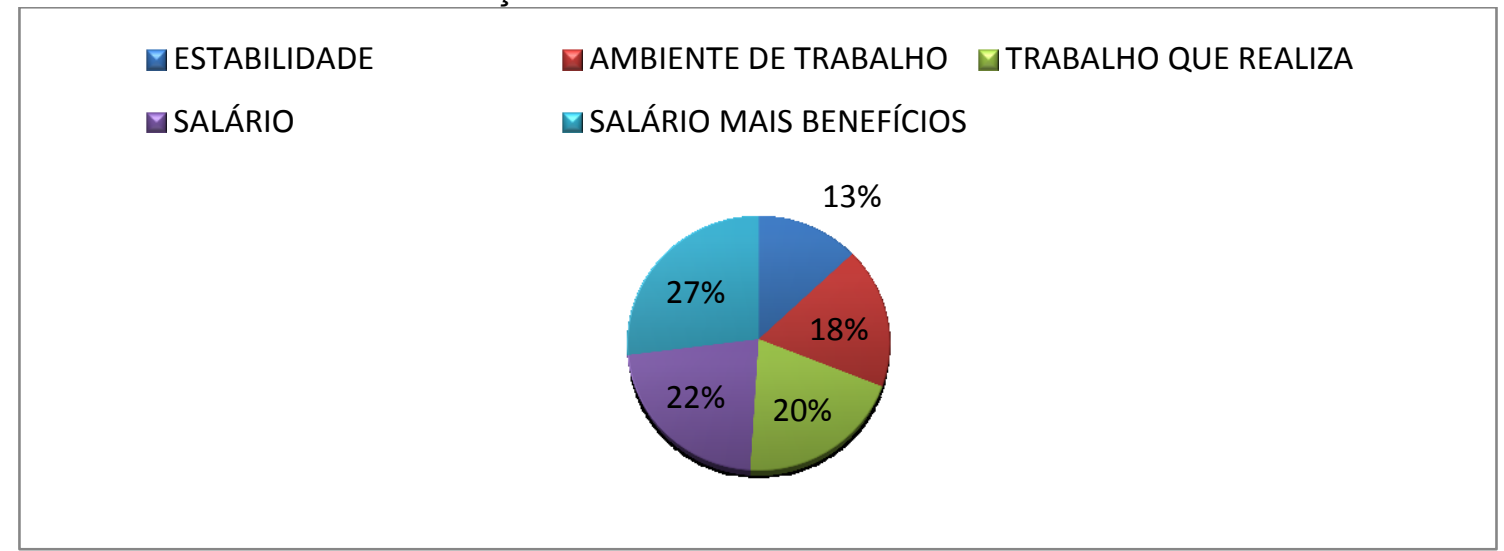

Fonte: Dados da pesquisa (2012)

A empresa pode contribuir com alguns fatores para a motivação, mas a motivação esta dentro de cada pessoa e cada um se motiva de uma forma. Tem pessoas que se motivam com um bom relacionamento com os colegas do setor, outras fazendo o trabalho que gosta, outras pessoas se sentem motivados apenas por ter a garantia de ter o trabalho fixo. E tem os trabalhadores que se motivam com o salário e com os benefícios, mas o que motiva um colaborador pode não motivar o outro, isso esta relacionada à cultura ou à necessidade das pessoas e da empresa. Isso esta evidente na pesquisa, os percentuais estão próximos apesar de ter fatores distintos. A organização tem que buscar a melhoria contínua no geral da empresa, sendo nos processos, na tecnologia, no produto, no gerenciamento assim como na gestão de pessoas para reter os talentos. 


\section{APRESENTAÇÃO E ANÁLISE DOS DADOS PESQUISA DE SATISFAÇÃO}

No final do Programa Qualidade de Vida do Trabalhador foi aplicado um segundo questionário, uma pesquisa de satisfação, para medir a satisfação dos participantes para possíveis melhorias.

Gráfico 13 - Avaliação do programa de qualidade de vida

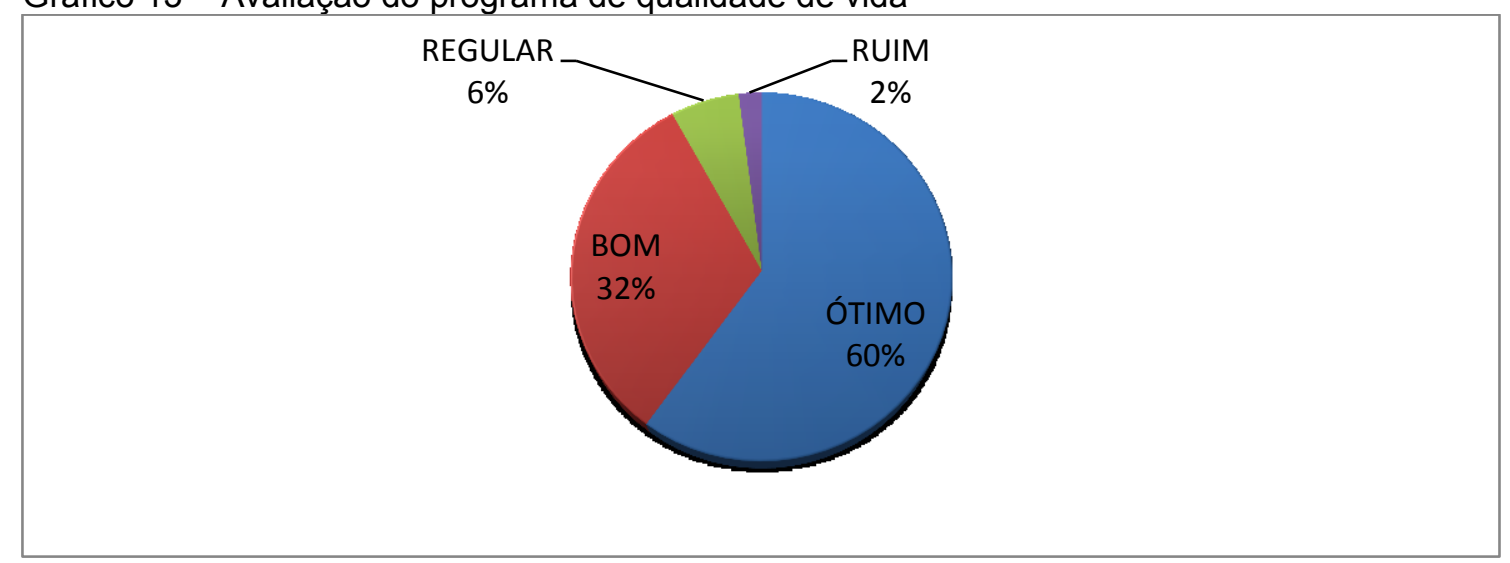

Fonte: Dados da pesquisa (2012)

As pessoas têm culturas e necessidades diferentes como já foi mencionado, quando se realiza um programa as expectativas são diferentes, e isso é evidente no grau de satisfação com o resultado da pesquisa. Uns querem foco maior no exercício físico, outros na alimentação, e outros esperam uma assistência médica melhor. Assim como há os colaboradores que tem preferência pelo foco em cultura, há também os funcionários que, talvez por suas necessidades básicas serem maiores, fazer um programa cultural com a família muitas vezes fica em segundo plano, até mesmo pela questão financeira. A questão financeira e a prioridades das necessidades estão relacionadas também quando referenciamos os outros pontos do programa e a motivação. Para as pessoas que não tem condições o que o programa da qualidade de vida oferece é muito significativo, e para as pessoas com mais condições talvez ficassem mais satisfeitas com o programa se ele oferece algo maior, como um treinamento com qualificação, que acaba acontecendo, mas não no geral. 
Gráfico 14 - Os objetivos para melhorar a saúde foram atingidos

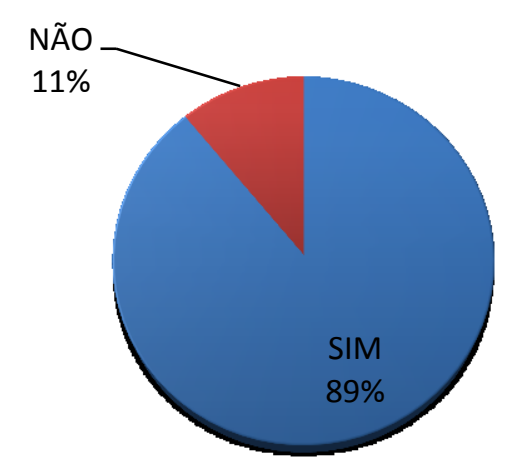

Fonte: Dados da pesquisa (2012)

Como o programa disponibilizou uma requisição médica para que fossem realizados todos os exames, foi possível analisar em quais pontos as pessoas precisariam trabalhar se seriam na prática do exercício ou na dieta pela questão de estética ou por um problema de saúde como colesterol, diabetes e pressão alta. Os percentuais dentro desses dois pontos foram de $37 \%$ pela questão saúde e $63 \%$ pela questão de estética e sedentarismo.

Gráfico 15 - Os objetivos definidos com exercícios físicos foram atingidos

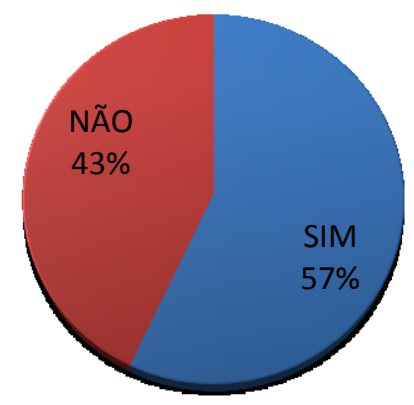

Fonte: Dados da pesquisa (2012)

Como normalmente acontece no início todos começam a praticar exercícios muito animados, mas no decorrer do programa muda a estação, acaba diminuindo a disponibilidade de tempo por consequência de outras atividades, e a sazonalidade influência. $E$ as pessoas que já tinham o hábito ou adotaram realmente o hábito de praticar exercícios continuaram a praticar, $57 \%$ alcançaram os objetivos. 
Gráfico 16 - Seguiu dieta para ter a alimentação mais saudável

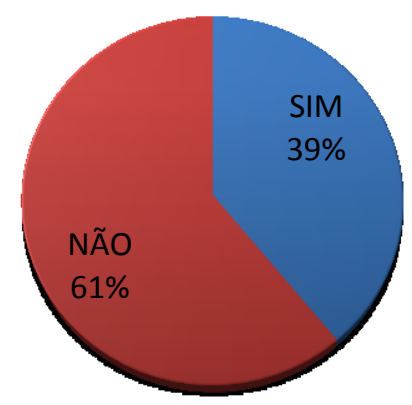

Fonte: Dados da pesquisa (2012)

Outra questão de cultura e hábito, na maioria dos casos a dieta é realmente seguida quando tem alguma doença de risco, como a diabetes, colesterol e pressão alta, mas ainda se não houver a manutenção as pessoas acabam deixando de fazer a dieta assim que a doença ameniza. Na questão de estética as dietas são seguidas até atingir o objetivo, e depois as pessoas acabam relaxando e perdendo totalmente os resultados, o que demonstra o percentual de $61 \%$. Quando na criação as pessoas aprendem a ter uma alimentação saudável com frutas, verduras, tomando muita água, e consumindo gordura e fritura em intervalos é mais fácil de manter a dieta, e quando as pessoas com força de vontade adquirem a dieta para uma alimentação melhor como hábito é possível obter bons resultados. Um dos benefícios da empresa é a cesta básica, além de ter alimentos saudáveis é acompanhada de receitas que podem ser feitas com os próprios produtos da cesta.

Gráfico 17 - Procurou adquirir conhecimento

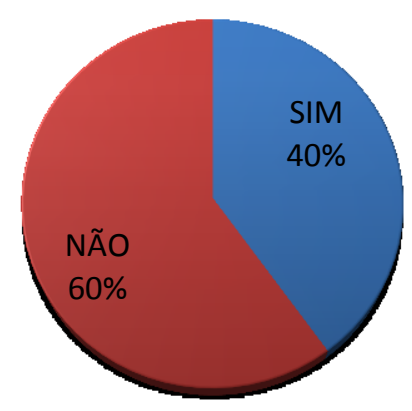

Fonte: Dados da pesquisa (2012)

Ágora: R. Divulg. Cient., v. 18, n. 2, p. 64-90, dez. 2011 (ISSN 2237-9010) 
Para as organizações uma forma de agregar valor é investir em treinamentos e capacitação para seus colaboradores, e a busca de conhecimento também é uma forma de agregar valor pessoal. "Investir nas pessoas significa dar a elas condições para que possam prosperar e viver com qualidade" (MAIA JUNIOR, 2012, p. 57).

Maia Junior e Stefano (2012) afirma que na Revolução Industrial as empresas têxteis na Inglaterra, provaram que a alta produtividade resultava de trabalhadores capacitados e tecnologia.

Hoje, são necessários cinco brasileiros para produzir a mesma riqueza que um americano, apesar dos trabalhadores brasileiros trabalharem mais, a questão é o resultado em termos de produção, a qualidade do trabalho. Isso acontece porque os americanos já chegam prontos na empresa, investem na educação desde sempre, segundo Maia Junior e Stefano (2012).

Gráfico 18 - Atividades do programa trouxeram benefícios para sua vida

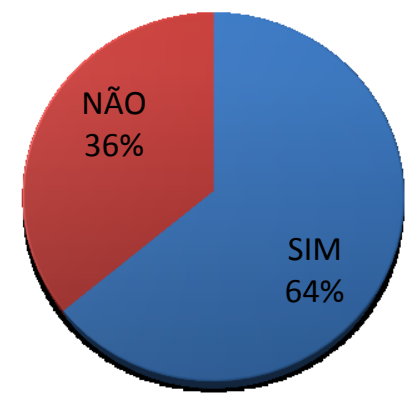

Fonte: Dados da pesquisa (2012)

A intenção de um programa de qualidade de vida é melhorar a qualidade de vida no trabalho, a qualidade de vida pessoal, com a família e social. E muitas vezes o estresse em todos esses aspectos é gerado por alguma doença ou insatisfação, e isso pode ser monitorado e controlado por exames médicos, alimentação saudável, prática de exercícios e treinamentos de aperfeiçoamento. Essas ações deveriam ser tomadas pelo indivíduo como hábito para ter uma melhor qualidade de vida, mas isso não acontece, e é uma alternativa para agregar valor na organização. E ainda citando a cultura, as pessoas que adotaram o hábito e seguiram o programa obtiveram bom resultado (64\%), e as pessoas que iniciaram o programa, mas não foram até o fim não tiveram nenhum resultado $(36 \%)$. 
Gráfico 19 - O programa fez alguma diferença no seu setor

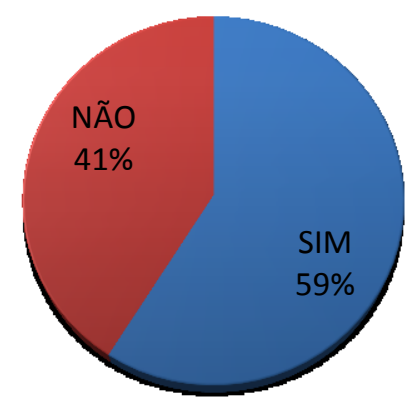

Fonte: Dados da pesquisa (2012)

Quando há a tentativa ou a experiência da implantação de uma novidade sempre acontece modificações no ambiente, no início o conflito, pois tem as pessoas que reagem bem as mudanças e tem outras que não, depois a empolgação, daí amorna e continuam até o fim apenas os que são comprometidos e motivados.

E em decorrência de treinamentos com líderes e a tentativa de trazer diferentes conhecimentos para os liderados implicou em mudanças, muitas pessoas saíram e as pessoas que entraram tem treinamento de integração para ficarem cientes das mudanças. A questão da comunicação também foi muito trabalhada nesse ano de 2012, pois a comunicação transparente é o caminho para o sucesso de um programa numa empresa.

Gráfico 20 - Modificações no setor para melhorar o ambiente de trabalho

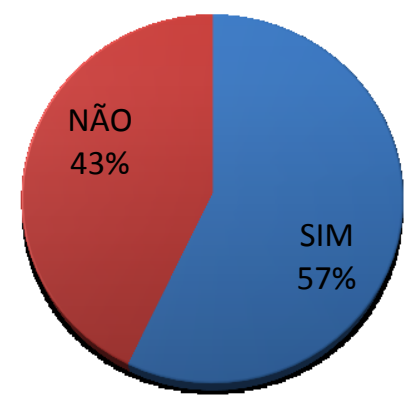

Fonte: Dados da pesquisa (2012)

Aconteceram pequenas mudanças, mais significativas e muitas vezes não percebidas pelos trabalhadores, como mostra o percentual de $57 \%$ dos Ágora: R. Divulg. Cient., v. 18, n. 2, p. 64-90, dez. 2011 (ISSN 2237-9010) 
trabalhadores que perceberam as modificações. Como bebedouros novos e com maior capacidade que foram adquiridos e é uma necessidade grande, torneiras e vazamentos arrumados nos banheiros, máquinas foram adquiridas, tanto para produção como para administrativo e controle de qualidade. Além dos treinamentos e como já mencionando a melhora da comunicação na transmissão de informações.

Gráfico 21 - Continuação do programa em 2013

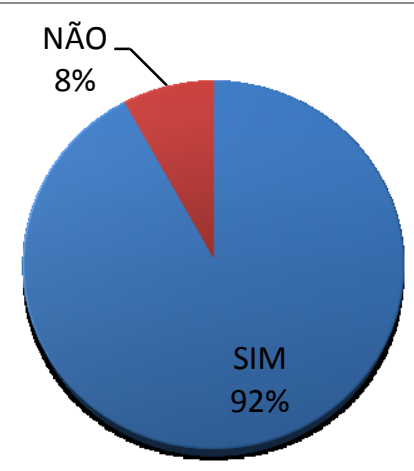

Fonte: Dados da pesquisa (2012)

No decorrer do programa é perceptível como a cultura das pessoas, assim como da organização, influencia em qualquer mudança na empresa. E que qualquer ação diferente adotada tem que passar por um trabalho de sensibilização das pessoas é necessário comunicar de forma clara e não deixar dúvidas até pela questão que de qualquer forma gera conflito, ainda pela cultura das pessoas, de como foram criadas, da religião, da região entre outras coisas. Não existe como mudar a cultura da organização do dia pra noite, até porque os valores têm que ser mensuráveis e de acordo com a realidade da empresa, assim também acontece com os trabalhadores.

Os novos colaboradores já entram no momento que o programa esta acontecendo, então conhecem a "nova cultura" da empresa, mais simples do que para os trabalhadores antigos que passam por essa mudança de valores. Alguns interpretando como motivação e outros como insatisfação, mas como este programa foi realizado com uma amostra de pessoas, e quando as que não obtiveram resultados viram o resultado alcançado pelos que seguiram o programa certo demonstraram interesse por participar de novo e os demais por continuar a participar. 
A intenção é realizar o programa para todos os colaboradores, e incentiva-los a adotar as práticas do programa como hábito.

Segundo Paraíso e Cavalcanti (2012, p.4).

\begin{abstract}
Para formar o hábito de consumir legumes e verduras, as famílias devem estimular os bebês e as crianças menores a provar uma variedade desses alimentos logo no primeiro ano de vida. Com isso, inúmeros benefícios são obtidos para a saúde como um todo, diminuindo consideravelmente o risco de obesidade, diabetes, hipertensão e doenças coronarianas.
\end{abstract}

Assim como uma criança deve ser estimulada a ter bons hábitos desde os primeiros anos de vida, quando funcionário é contratado ele deve ser integrado aos valores da organização assim como esses valores devem ser aperfeiçoados e integrados aos que já estão na empresa.

\title{
CONSIDERAÇÕES FINAIS
}

Quando o projeto foi iniciado a perspectiva era totalmente diferente do que foi concluído com a pesquisa no decorrer do programa qualidade de vida. A princípio o pensamento era de que tudo seria fácil, e que o problema era a organização que não buscava diferenciais para os trabalhadores, mas além desse único suposto problema há a cultura e a motivação de empregado e empresa, que foi se destacando no desenvolvimento da aplicação do projeto.

O programa foi iniciado com a intenção de agregar valor para a empresa em relação ao empregado, na valorização do recurso humano, e também a responsabilidade social que visa o desenvolvimento social. As ações foram sendo aperfeiçoadas no andamento do programa, e foi durante esse processo que os pontos que precisavam ser melhorados foram destacados. $\mathrm{E}$ foi possível perceber que para o sucesso de qualquer mudança dentro de uma organização é necessário uma comunicação clara e simples, e um trabalho de sensibilização. Para despertar o interesse das pessoas é necessário passar a importância e o conhecimento para que as mesmas queiram ou não adotar como hábito.

A cultura e a motivação foram questões destaque do programa, pois foram nesses pontos que foram encontradas dificuldades. Além de ter pessoas com culturas distintas, a organização apresenta sua cultura que também é diferente. $\mathrm{Na}$ 
implantação de algo novo, ambas as culturas têm de ser trabalhadas, pois na empresa haverá mudanças nos valores e das pessoas também.

A motivação pode ser despertada, mas depende de cada pessoa, porque somente cada um tem a capacidade de se motivar. E o que motiva uma pessoa pode não ser motivador para outra. No programa foi trabalhado com três pontos centrais, o ideal era que os três fossem seguidos, mas se o trabalhador adotasse pelo menos um já era o primeiro passo para adotar os outros dois. Além de outras ações que foram adotadas como informativos sobre saúde, beleza e conhecimentos gerais.

Depois desse projeto usando uma amostra de funcionários ficou mais claro como realizar o programa para a empresa toda, houve aspectos positivos e negativos e ambos ainda serão melhorados para termos efetividade no Programa de Qualidade de Vida para os funcionários.

\section{REFERÊNCIAS}

BELEZA E SAÚDE. Exercícios físicos. 2012. Disponível em: <http://belezaesaude.dae.com.br/exercicios-fisicos/>. Acesso em 29 out. 2012.

CHELEGON, Hamilton. SA 8000? NBR 16001 ou ISO 26000? Qual a tua empresa merece? - 2008. Disponível em:<Web Artigos>. Acesso em: 06 fev. 2012.

DE MASI, Domenico. 0 futuro do trabalho: fadiga e ócio na sociedade pósindustrial. 3 ed., Rio de Janeiro: Editora José Olympio Ltda. e Brasília: Edit. da UNB, 2000.

DOLAN, Simon L. Estresse, auto-estima, saúde e trabalho. Rio de Janeiro: Editora Qualitymark, 2006.

DRUCKER, P. F. Fator Humano e desempenho: o melhor de Peter F. Drucker sobre administração. São Paulo: Pioneira, 1981.

MAIA JUNIOR, Humberto; As pessoas fazem a diferença. Revista Exame, São Paulo: Abril, v. 1025, n. 19, 03 out. 2012. Quinzenal.

MELO NETO, Francisco Paulo; FROES, César. Responsabilidade social \& cidadania empresarial: administração do terceiro setor. Rio de Janeiro: Editora Qualitymark, 2001. 
PARAISO, Solange; CAVALCANTI, Ney. Vida saudável: Qualidade de vida nas empresas. 2012. Disponível em: <http://www.folhape.com.br/cms/opencms/folhape/ pt/cultura/col/vidasaudavel/arq/2012/09/0001.html>. Acesso em: 15 out, 2012.

STEFANO, Fabiane; MAIA JUNIOR, Humberto; Por que somos tão improdutivos. Revista Exame, São Paulo: Abril, v. 1025, n. 19, 03 out. 2012. Quinzenal.

UNIÃO FOSFOREIRA. Manual da qualidade. Curitibanos, 2011. Trabalho não publicado

USP, Comissão de Direitos Humanos da. Estratégia global em alimentação saudável, atividade física e saúde. 2004. Disponível em: <Biblioteca Virtual dos Direitos Humanos>. Acesso em: 08 fev. 2012.

TACHIZAWA, T. Gestão ambiental e responsabilidade social corporativa: estratégias de negócios focadas na realidade brasileira. São Paulo: Atlas, 2002. 